\title{
Heat transfer in flow through branching tubes
}

\author{
Antonio F. Miguel \\ Department of Physics, \\ Institute of Earth Sciences (ICT) - Pole of Evora, \\ University of Evora, \\ Rua Romao Ramalho 59, \\ Evora 7000-671, Portugal \\ Email: afm@uevora.pt
}

\begin{abstract}
Allometric scaling relations for how branching tubes deliver fluid are often based on the assumption of isothermal conditions which are not always fulfilled. This work reports on the sizes of branching tubes for fluid flow subjected to constant wall heat flux. It explores how the delivery of fluid and heat influences the optimal size of a tube and the optimal configuration of branching tubes for both laminar and turbulent flow. Besides, it presents an analytical basis for evaluation of optimal size of tubes that minimise the power loss associated with the pumping power and the heat transfer. The findings obtained in this study may have important implications for design of systems with minimum thermodynamic losses.
\end{abstract}

Keywords: optimal design; bifurcated tubes; heat flux; laminar and turbulent flows; minimum expenditure of power; constructal law.

Reference to this paper should be made as follows: Miguel, A.F. (2018) 'Heat transfer in flow through branching tubes', Int. J. Hydromechatronics, Vol. 1, No. 2, pp.172-181.

Biographical notes: Antonio F. Miguel is an Associate Professor of Physics from the School of Science and Technology at the University of Évora, and a member of the Institute of Earth Sciences, Portugal. He received his BSc and MSc from the University of Évora. In 1994, he attended the graduate school at WU-R, the Netherlands, completing his $\mathrm{PhD}$ in 1998. In his research, he investigates a wide range of topics in fluid dynamics, thermodynamics, heat transfer and porous media. He is the author of three books (Porous Media and Tree-Shaped Networks published by Springer in 2004 and 2018, and Constructal Theory of Organisation in Nature published by UNIL in 2006), and over 80 peer-refereed articles.

\section{Introduction}

Branching flow designs are widespread occurrences in nature and engineering (Bejan, 2000, 2017; Rodríguez-Iturbe and Rinaldo, 1997; McCulloh et al., 2003; Bejan and Lorente, 2008, 2013; Miguel and Rocha, 2018). They involve several geometrical configurations and flow regimes (Miguel, 2018). Very often the design these natural system provides motivation for the structure of manmade systems for cooling (Escher et al., 2009; Rocha et al., 2014; Cetkin et al., 2011, 2015), fluid delivery (Kim et al., 
2006; Lee et al., 2009), energy generation (Senn and Poulikakos, 2004; Vargas et al., 2004; Damian-Ascencio et al., 2017), energy storage (Ziaei et al., 2015; Bejan et al., 2016), catalysis (Coppens, 2012), self-healing composite materials (Bejan et al., 2006; Lee et al., 2013, 2018), etc.

While it is generally accepted that the optimum conditions, governing the ratio of diameters of the tubes in a branching network, is achieved when the cube of the parent tube diameter is equal to the sum of the cubes of the daughter tube diameters [i.e., the Hess-Murray law (Hess, 1917; Murray, 1926)], evidence has shown that this relationship is not applied universally to all branching flow systems (Miguel and Rocha, 2018). Indeed, in studies examining branching tubes of permeable walls, turbulent flows and flows of non-Newtonian fluids, distinct allometric scaling relations were found (Bejan et al., 2000; Revellin et al., 2009; Miguel, 2015, 2016a, 2016b, 2018; Pepe et al., 2017). A comprehensive review of the most important advances that have been made in bifurcated flow networks are presented by Miguel and Rocha (2018). Based on the above, accumulating evidence indicates that the Hess-Murray rule is valid only on the assumption of an isothermal Hagen-Poiseuille flow, of a Newtonian fluid under a steady constant pressure gradient, through a straight tube of rigid and non-permeable walls.

Most processes involve heat generation and heat exchange between systems. In fact, many flow systems are not isothermal, since a part of the external energy is converted into internal energy or vice-versa. In this paper, we tackle the question how optimal configuration of bifurcating tubes is influenced by both fluid flow and the heat transfer rate. A general method is developed with emphasis on total expenditure of power required. Minimisation of total power subject to a volume constraint leads to an optimal rule between the sizes of tubes.

\section{Theoretical background}

\subsection{Total expenditure of power for a tube}

To begin with, consider the case of a fluid flow through a tube whose wall is subjected to a constant heat flux. Analysing from a thermodynamics point of view, losses can be related with both fluid and heat streams. The losses associated with fluid flow can be targeted according to the entropy generation rate due to the fluid flow $\left(=\Phi_{\mathrm{h}} / \mathrm{T}\right)$ where $\mathrm{T}$ is the temperature, and $\Phi_{\mathrm{h}}$ is the hydraulic power required to pump the fluid through the tube defined as

$$
\Phi_{\mathrm{h}}=\phi^{2} \mathrm{Z}
$$

Here $\mathrm{Z}$ is the impedance of the tube given by $\Delta \mathrm{p} / \phi$ (Miguel, 2018) and

$$
\Delta \mathrm{p}=\mathrm{f}_{\mathrm{DW}} \frac{\mathrm{L}}{\mathrm{D}} \frac{\rho_{\mathrm{f}}}{2 \mathrm{~A}^{2}} \phi^{2}
$$

where $\mathrm{p}$ is the pressure, $\mathrm{D}$ is the diameter of the tube, $\mathrm{L}$ is the length of the tube, $\mathrm{A}$ is the cross-sectional area of the tube, $\rho_{\mathrm{f}}$ is the fluid density, and $\mathrm{f}_{\mathrm{DW}}$ is the Darcy-Weisbach friction factor. According to the Moody chart 


$$
\begin{aligned}
& \mathrm{f}_{\mathrm{DW}}=\frac{64}{\mathrm{Re}_{\mathrm{D}}^{\mathrm{n}}} \quad \mathrm{n}=1 \text { and } \mathrm{Re}_{\mathrm{D}} \leq 2100 \\
& \mathrm{f}_{\mathrm{DW}}=\frac{0.171 \varepsilon^{0317}}{\operatorname{Re}_{\mathrm{D}}^{\mathrm{n}}} \quad \mathrm{n}=0 ; 0.001 \leq \varepsilon \leq 0.03 \text { and } 10^{10}<\operatorname{Re}_{\mathrm{D}} \leq 10^{8}
\end{aligned}
$$

where $\operatorname{Re}_{\mathrm{D}}$ is the Reynolds number $\left(4 \rho_{\mathrm{f}} \phi / \pi \mathrm{D} \mu\right), \varepsilon$ is the relative roughness, and $\mu$ is the dynamic viscosity.

Besides fluid friction, heat transfer through a temperature difference also causes irreversibility. Assuming that the difference between the wall temperature and the bulk temperature of the fluid, $\Delta \mathrm{T}$, is much less than the wall temperature, $\mathrm{T}$, the entropy generation rate due to the flow of heat, $\mathrm{S}_{\mathrm{Q}}$, is

$$
\mathrm{S}_{\mathrm{Q}}=\frac{\mathrm{Q} \Delta \mathrm{T}}{\mathrm{T}^{2}}
$$

where Q is the heat flux conveniently expressed by the so-called Newton's law of cooling. The Stanton number is a dimensionless heat transfer number applied to flows with forced convective heat transfer, and $\mathrm{S}_{\mathrm{Q}}$ can be written in the form

$$
\mathrm{S}_{\mathrm{Q}}=\frac{2 \mathrm{AQ}^{2}}{\pi \rho_{\mathrm{f}} \mathrm{c}_{\mathrm{p}} \mathrm{T}^{2} \mathrm{DL} \phi \mathrm{St}}
$$

Here $\mathrm{St}$ is the Stanton number and $\mathrm{c}_{\mathrm{p}}$ is the heat capacity. From the definition of entropy (second law of thermodynamics), the power associated to heat transfer $\Phi_{Q}$ is given by

$$
\Phi_{\mathrm{Q}}=\mathrm{TS}_{\mathrm{Q}}
$$

Substituting equation (7) into equation (6) results in

$$
\Phi_{\mathrm{Q}}=\frac{2 \mathrm{AQ}^{2}}{\pi \rho_{\mathrm{f}} \mathrm{c}_{\mathrm{p}} \mathrm{TDL} \phi \mathrm{St}}
$$

The principle of superposition states that the power associated to sources of thermodynamic losses, acting together, is equal to the sum of the expenditure of power of each source acting alone. Therefore, according to equations (1) and (8) the power expended is

$$
\Phi=\phi^{2} \mathrm{Z}+\frac{2 \mathrm{AQ}^{2}}{\pi \rho_{\mathrm{f}} \mathrm{c}_{\mathrm{p}} \mathrm{TDL} \phi \mathrm{St}}
$$

\subsection{Total expenditure of power for bifurcating tubes}

Consider a symmetrically branched tube with a svelteness factor (i.e., the ratio of square root of the total external area occupied by the system to the cubic root of the total volume of the tubes) higher than the square root of 10 (Wechsatol et al., 2006). This is the criterion that has been adopted to consider that the hydraulic impedance at junction of tubes is much less than the hydraulic impedance of parent and daughter tubes.

The impedance of daughter tubes is in parallel (the equivalent impedance is the reciprocal of the sum of the reciprocals of the individual impedances), and the impedance 
of parent tube is in series with daughter tubes (Figure 1). The total impedance of the system is (Miguel, 2018)

$$
Z_{\text {total }}=Z_{p}+\frac{Z_{d}}{2^{2-n}}
$$

where the subscripts $\mathrm{p}$ and $\mathrm{d}$ mean parent and daughters tubes, respectively. Combining equations (2) and (10) one obtains

$$
\mathrm{Z}_{\text {total }}=\frac{16 \rho_{\mathrm{f}} \mathrm{f}_{\mathrm{DW}} \phi}{\pi^{2}}\left(\frac{\mathrm{L}_{\mathrm{p}}}{\mathrm{D}_{\mathrm{p}}^{5}}+\frac{1}{2^{2-\mathrm{n}}} \frac{\mathrm{L}_{\mathrm{d}}}{\mathrm{D}_{\mathrm{d}}^{5}}\right)
$$

Thus, the total expenditure of power is obtained substituting equation (11) into equation (9), which results in

$$
\Phi^{*}=\frac{16 f_{D W} \phi^{2}}{\pi^{2} c_{p} T}\left(\frac{L_{p}}{D_{p}^{5}}+\frac{1}{2^{2-n}} \frac{L_{d}}{D_{d}^{5}}\right)+\frac{Q^{* 2}}{2 S t}\left(\frac{D_{p}}{L_{p}}+2 \frac{D_{d}}{L_{d}}\right)
$$

with

$$
\Phi^{*}=\frac{\Phi}{\rho_{\mathrm{f}} \mathrm{c}_{\mathrm{p}} \mathrm{T} \phi} \text { and } \mathrm{Q}^{*}=\frac{\mathrm{Q}}{\rho_{\mathrm{f}} \mathrm{c}_{\mathrm{p}} \mathrm{T} \phi}
$$

where $\Phi^{*}$ and $Q^{*}$ are the dimensionless power and heat flux, respectively.

Under laminar flow conditions $f_{D W}$ is defined by equation (3), and using equation (12) we obtain

$$
\Phi^{*}=\left(\mathrm{C}_{\mathrm{f}} \frac{\mathrm{L}_{\mathrm{p}}^{2}}{\mathrm{D}_{\mathrm{p}}^{5}}+\frac{\mathrm{C}_{\mathrm{q}}}{2}\right) \frac{\mathrm{D}_{\mathrm{p}}}{\mathrm{L}_{\mathrm{p}}}+\left(\frac{\mathrm{C}_{\mathrm{f}}}{2}-\frac{\mathrm{L}_{\mathrm{d}}^{2}}{\mathrm{D}_{\mathrm{d}}^{5}}+\mathrm{C}_{\mathrm{q}}\right) \frac{\mathrm{D}_{\mathrm{d}}}{\mathrm{L}_{\mathrm{d}}}
$$

with

$$
\begin{aligned}
& \mathrm{C}_{\mathrm{f}}=\frac{256 \mu \phi}{\pi \rho_{\mathrm{f}} \mathrm{c}_{\mathrm{p}} \mathrm{T}} \\
& \mathrm{C}_{\mathrm{q}}=\frac{\mathrm{Q}^{* 2}}{\mathrm{St}}
\end{aligned}
$$

For $10^{6}<\mathrm{Re}_{\mathrm{D}} \leq 10^{8}$ (turbulent flow) combining equations (4) and (12) one obtains

$$
\Phi^{*}=\left(\mathrm{C}_{\mathrm{F}} \frac{\mathrm{L}_{\mathrm{p}}^{2}}{\mathrm{D}_{\mathrm{p}}^{6}}+\frac{\mathrm{C}_{\mathrm{q}}}{2}\right) \frac{\mathrm{D}_{\mathrm{p}}}{\mathrm{L}_{\mathrm{p}}}+\left(\frac{\mathrm{C}_{\mathrm{F}}}{4} \frac{\mathrm{L}_{\mathrm{d}}^{2}}{\mathrm{D}_{\mathrm{d}}^{6}}+\mathrm{C}_{\mathrm{q}}\right) \frac{\mathrm{D}_{\mathrm{d}}}{\mathrm{L}_{\mathrm{d}}}
$$

with

$$
\mathrm{C}_{\mathrm{F}}=\frac{2.74 \varepsilon^{0.317} \phi^{2}}{\pi^{2} \mathrm{c}_{\mathrm{p}} \mathrm{T}}
$$


Figure 1 Schematic representation of a symmetrical dichotomous flow system of tubes (see online version for colours)

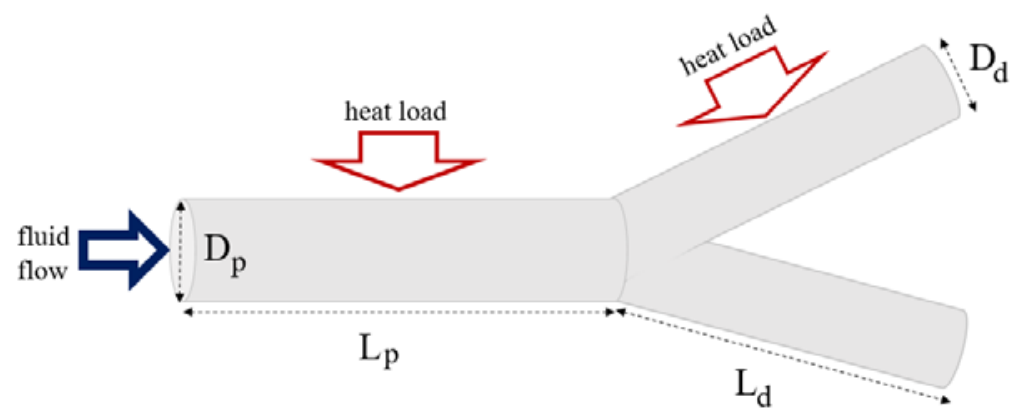

\section{Optimal structure of a bifurcating system of tubes}

\subsection{Single tubes for optimal hydraulic and thermal performances}

According to equations (14) and (17), the expenditure of power in parent and daughter single tubes holds with the following equations:

$$
\begin{aligned}
& \Phi^{*}=\left[\frac{a_{1} C_{f}}{L^{3}}\left(\frac{L}{D}\right)^{5}+b_{1} C_{q}\right] \frac{D}{L} \\
& \Phi^{*}=\left[\frac{a_{t} C_{F}}{L^{4}}\left(\frac{L}{D}\right)^{6}+b_{t} C_{q}\right] \frac{D}{L}
\end{aligned}
$$

with $a_{1}=a_{t}=1$ and $b_{1}=b_{t}=1 / 2$ for parent tubes, $a_{1}=1 / 2, a_{t}=1 / 4$ and $b_{1}=b_{t}=1$ for daughter tubes. Here the subscripts 1 and $t$ mean laminar and turbulent flow regimes, respectively. According to the constructal law (Bejan, 2000; Bejan and Lorente, 2008), maximum performance means minimum power destroyed under space constraints (volume, area, or length). For these 3D systems, we consider that the volume $\mathrm{V}$ occupied by the tubes is a constant

$$
\mathrm{V}=\mathrm{c} \frac{\pi}{4} \mathrm{D}^{2} \mathrm{~L}
$$

with $\mathrm{c}=1$ and $\mathrm{c}=2$ for parent and daughter tubes, respectively.

The goal is to obtain the size of tubes $(\mathrm{D}, \mathrm{L})$ that bears the minimum power dissipation. For each tube, the necessary condition for a minimum expenditure of power is that the first-order derivative of the objective function $\Phi$ is zero, and second-order derivative is positive. The chain rule allows the differentiation of composite functions, and

$$
\frac{\mathrm{d} \Phi^{*}}{\mathrm{dD}}=\frac{\mathrm{d} \Phi^{*}}{\mathrm{dL}} \frac{\mathrm{dL}}{\mathrm{dD}}
$$

By using equations (19) and (21) and equations (20) and (21), differentiating $\Phi^{*}$ with respect to $\mathrm{D}$ yields 


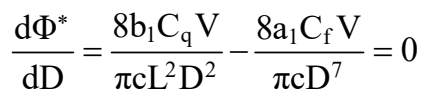

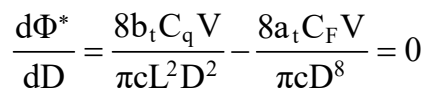

From these equations (first-order derivatives), it can be seen that the second-order derivatives are positives, thus $\mathrm{D}$ and $\mathrm{L}$ corresponds to the minimum expenditure of power. By setting equations (23) and (24) equal to zero and solving for D/L, we obtain

$$
\begin{aligned}
& \frac{D}{L}=\left(\frac{a_{1} C_{f}}{b_{1} C_{q} L^{3}}\right)^{1 / 5} \\
& \frac{D}{L}=\left(\frac{a_{t} C_{F}}{b_{t} C_{q} L^{4}}\right)^{1 / 6}
\end{aligned}
$$

Notice that while optimal $\mathrm{D} / \mathrm{L}$ depends on fluid flow rate, these equations also indicate that the optimal size is proportional $\mathrm{St}^{1 / 5}$ but inversely proportional to $\mathrm{Q}^{* 2 / 5}$ in laminar flow (equation 25), whereas $\mathrm{St}^{1 / 6}$ and $\mathrm{Q}^{*-1 / 3}$ typify turbulent flow [equation (26)].

\subsection{Optimum way to connect parent and daughter tubes together}

Our goal is to maximise both the hydraulic and thermal performances in a system of bifurcating tubes (Figure 1). Maximum performance of entire assembly of tubes means minimum total expenditure of power under space constraints (Bejan, 2000; Bejan and Lorente, 2008). The total volume, $\mathrm{V}_{\text {total }}$, occupied by the tubes is constrained

$$
\mathrm{V}_{\text {total }}=\text { constant }=\frac{\pi}{4} \mathrm{D}_{\mathrm{p}}^{2} \mathrm{~L}_{\mathrm{p}}+2 \frac{\pi}{4} \mathrm{D}_{\mathrm{d}}^{2} \mathrm{~L}_{\mathrm{d}}
$$

The conditions for minimum expenditure of power are $\mathrm{d} \Phi^{*} / \mathrm{dD}=0$ and $\mathrm{d}^{2} \Phi^{*} / \mathrm{dD}^{2}>0$. As equations (14) and (17) depend both on the sizes of parent and daughter tubes, the chain rule helps to find the derivative of these composite functions. Differentiation of these equations with respect to $D_{d}$, using the chain rule, yields

$$
\frac{\mathrm{d} \Phi^{*}}{\mathrm{dD}_{\mathrm{d}}}=\frac{\mathrm{d} \Phi^{*}}{\mathrm{dD}_{\mathrm{p}}} \frac{\mathrm{dD}_{\mathrm{p}}}{\mathrm{dD}_{\mathrm{d}}}+\frac{\mathrm{d} \Phi^{*}}{\mathrm{dD}_{\mathrm{d}}}
$$

According to equation (27)

$$
\mathrm{D}_{\mathrm{p}}=\left(\frac{4 \mathrm{~V}_{\text {total }}-2 \pi \mathrm{D}_{\mathrm{d}}^{2} \mathrm{~L}_{\mathrm{d}}}{\pi \mathrm{L}_{\mathrm{p}}}\right)^{1 / 2}
$$

and for $\mathrm{Re}_{\mathrm{D}} \leq 2,100$, substituting derivatives of equations (14) and (29) into (28) results in

$$
\frac{d \Phi^{*}}{d D_{d}}=\left(\frac{8 C_{f} L_{p}}{D_{p}^{5}}-\frac{C_{q}}{L_{p}}\right) \frac{L_{d} D_{d}}{L_{p} D_{p}}+\frac{C_{q}}{L_{d}}-\frac{2 C_{f} L_{d}}{D_{d}^{5}}
$$




$$
\frac{\mathrm{d}^{2} \Phi^{*}}{\mathrm{dD}_{\mathrm{d}}^{2}}=\frac{8 \mathrm{C}_{\mathrm{f}} \mathrm{L}_{\mathrm{d}}}{\mathrm{D}_{\mathrm{p}}^{6}}+\frac{10 \mathrm{C}_{\mathrm{f}} \mathrm{L}_{\mathrm{d}}}{\mathrm{D}_{\mathrm{d}}^{6}}-\frac{\mathrm{C}_{\mathrm{q}} \mathrm{L}_{\mathrm{d}}}{\mathrm{L}_{\mathrm{p}}^{2} \mathrm{D}_{\mathrm{p}}}
$$

As $D_{p}$ and $D_{d}$ are much lower than $1 \mathrm{~m}, \mathrm{~d}^{2} \Phi^{*} / \mathrm{dD}_{\mathrm{d}}^{2}$ is positive. Then, the minimum expenditure of power is obtained by setting equation (30) equal to zero, and solving for diameters we obtain

$$
\frac{D_{d}}{D_{p}}=\left[\frac{\frac{1}{4}-\frac{C_{q} D_{p}^{5}}{8 C_{f} L_{d}^{2}}\left(\frac{D_{d}}{D_{p}}\right)^{5}}{1-\frac{C_{q} D_{p}^{5}}{8 C_{f} L_{p}^{2}}}\right]^{1 / 6}
$$

Equation (32) is implicit and it has to be solved using an iterative procedure. It is also important to note that once $\mathrm{C}_{\mathrm{q}}=0$ (isothermal case), the equation becomes explicit and reproduces the old result $\left(D_{d} / D_{p}=2^{-1 / 3}\right)$, the so-called Hess-Murray law (Murray, 1926).

We now turn our attention to flows of Reynolds number ranging from $10^{6}$ to $10^{8}$. According to equation (4) the Darcy-Weisbach friction factor is independent of Reynolds number. Substituting derivatives of equations (17) and (29) into equation (28) yields

$$
\frac{D_{d}}{D_{p}}=\left[\frac{\frac{1}{8}-\frac{C_{q} D_{p}^{6}}{10 C_{F} L_{d}^{2}}\left(\frac{D_{d}}{D_{p}}\right)^{6}}{1-\frac{C_{q} D_{p}^{6}}{10 C_{f} L_{p}^{2}}}\right]^{1 / 7}
$$

Notice that equation (33) is also an implicit equation and needs to be solved iteratively. Since $\mathrm{C}_{\mathrm{q}}=0$, the ratio between the diameters of daughter and parent tubes are given by the simple expression $D_{d} / D_{p}=2^{-3 / 7}$, that agrees with the results obtained by Uylings (1977) and Bejan et al. (2000).

Maximal efficiency of energy requires equipartition of thermodynamic forces, i.e., forces uniformly distributed across system. Therefore, optimal branching leads to the same contribution of parent and daughter tubes for the total impedance and total pressure, but also for the total volume (see for example, Losa et al., 2002; Miguel, 2015). Thus, it is remarkable that despite the complexity of design of a bifurcating system in the $3 \mathrm{D}$ space, there is a simple representation of the physics properties. Accordingly, following equation (27) one obtains $\mathrm{D}_{\mathrm{p}}^{2} \mathrm{~L}_{\mathrm{p}}=2 \mathrm{D}_{\mathrm{d}}^{2} \mathrm{~L}_{\mathrm{d}}$. Substituting equations (32) and (33) into this equation results in

$$
\frac{L_{d}}{L_{p}}=\left[\frac{2-\frac{C_{q} D_{d}^{5}}{C_{f} L_{p}^{2}}\left(\frac{L_{p}}{L_{d}}\right)^{2}}{1-\frac{C_{q} D_{p}^{5}}{8 C_{f} L_{p}^{2}}}\right]^{-1 / 3} \quad \operatorname{Re}_{D} \leq 2100
$$




$$
\frac{\mathrm{L}_{\mathrm{d}}}{\mathrm{L}_{\mathrm{p}}}=\left[\frac{2^{1 / 2}-\frac{2^{7 / 2} \mathrm{C}_{\mathrm{q}} \mathrm{D}_{\mathrm{d}}^{6}}{10 \mathrm{C}_{\mathrm{F}} \mathrm{L}_{\mathrm{p}}^{2}}\left(\frac{\mathrm{L}_{\mathrm{p}}}{\mathrm{L}_{\mathrm{d}}}\right)^{2}}{1-\frac{\mathrm{C}_{\mathrm{q}} \mathrm{D}_{\mathrm{p}}^{6}}{10 \mathrm{C}_{\mathrm{F}} \mathrm{L}_{\mathrm{p}}^{2}}}\right]^{-2 / 7} \quad 10^{6}<\mathrm{Re}_{\mathrm{D}} \leq 10^{8}
$$

Equations (34) and (35) represents the optimal ratio of successive tube lengths for both the hydraulic and thermal performances. It is important to note that, if $\mathrm{C}_{\mathrm{q}}=0$, then equations (34) and (35) reduce to $\mathrm{L}_{d} / \mathrm{L}_{\mathrm{p}}=2^{-1 / 3}$ and $\mathrm{L}_{\mathrm{d}} / \mathrm{L}_{\mathrm{p}}=2^{-1 / 7}$, respectively, and agrees with the findings of Bejan et al. (2000).

\section{Final remarks}

Branching flow networks of tubes are widespread occurrences in nature and engineering, because are the best path if the purpose is to connect one point (source or sink) with an infinity of points (volume, area). A common situation encountered is also heat transfer to fluid flowing through tubes.

The structural characteristics of the bifurcating tubes are important to ensure continued proper functioning of the flow system. Here, we have presented a generalised approached that leads to analytical expressions for the optimum diameter-length ratio of individual tubes, and the optimum daughter-parent sizes ratio of branching tubes, under different fluid flow conditions and exposed to different heat fluxes. Our generalised expressions for branching tubes are equivalent to Hess-Murray's law, and Uylings (1977) and Bejan et al. (2000) equations in absence of heat fluxes.

Equations (32) and (33) can be used to derive expressions for the optimum branching angles of daughter tubes. The optimum angles are equal to two times the inverse cosine function of half of optimal ratio of successive tube diameters.

In summary, our new relations can be applied to design to endow systems with minimum thermodynamic losses. In addition, our model may lead to deeper understanding of natural bifurcated networks. Finally, the design rules presented here and that provides geometric optimisation can also be viewed as a manifestation of general principle of physics, such as the so-called equipartition of thermodynamic forces.

\section{Acknowledgements}

This work is co-funded by the European Union through the European Regional Development Fund under COMPETE 2020 and by the ICT project (UID/GEO/04683/2013) reference POCI-01-0145-FEDER-007690.

\section{References}

Bejan, A. (2000) Shape and Structure, from Engineering to Nature, Cambridge University Press, Cambridge.

Bejan, A. (2017) 'Evolution in thermodynamics', Appl. Phys. Rev., Vol. 4, No. 1, p.011305.

Bejan, A. and Lorente, S. (2008) Design with Constructal Theory, Wiley, Hoboken. 
Bejan, A. and Lorente, S. (2013) 'Constructal law of design and evolution: physics, biology, technology, and society', J. Appl. Phys., Vol. 113, No. 15, p.151301.

Bejan, A., Lorente, S. and Wang, K.M. (2006) 'Networks of channels for self-healing composite materials', Journal of Applied Physics, Vol. 100, No. 3, p.033528.

Bejan, A., Rocha, L.A.O. and Lorente, S. (2000) 'Thermodynamic optimization of geometry: T and Y-shaped constructs of fluid streams', Int. J. Therm. Sci., Vol. 39, Nos. 9-11, pp.949-960.

Bejan, A., Ziaei, S. and Lorente, S. (2016) 'Distributed energy storage: time-dependent tree flow design', Journal of Applied Physics, Vol. 119, No. 18, p.184901.

Cetkin, E., Lorente, S. and Bejan, A. (2011) 'Vascularization for cooling and mechanical strength', Int. J. Heat Mass Trans., Vol. 54, Nos. 13-14, pp.2774-2781.

Cetkin, E., Lorente, S. and Bejan, A. (2015) 'Vascularization for cooling and reduced thermal stresses', Int. J. Heat Mass Trans., Vol. 80, No. 1, pp.858-864.

Coppens, M.O. (2012) 'A nature-inspired approach to reactor and catalysis engineering', Current Opinion in Chemical Engineering, Vol. 1, No. 3, pp.281-289.

Damian-Ascencio, C.E., Saldaña-Robles, A., Hernandez-Guerrero, A. and Cano-Andrade, S. (2017) 'Numerical modeling of a proton exchange membrane fuel cell with tree-like flow field channels based on an entropy generation analysis', Energy, Vol. 133, No. 1, pp.306-316.

Escher, W., Michel, B. and Poulikakos, D. (2009) 'Efficiency of optimized bifurcating tree-like and parallel microchannel networks in the cooling of electronics', Int. J. Heat Mass Trans., Vol. 52, Nos. 5-6, pp.1421-1430.

Hess, W.R. (1917) 'Über die periphere Regulierung der Blutzirkulation', Pflüger's Archiv für die Gesamte Physiologie des Menschen und der Tiere, Vol. 168, pp.439-490.

Kim, S., Lorente, S. and Bejan, A. (2006) 'Vascularized materials: tree-shaped flow architectures matched canopy to canopy', Journal of Applied Physics, Vol. 100, No. 6, p.063525.

Lee, J., Kim, Y., Lorente, S. and Bejan, A. (2013) 'Constructal design of a comb-like channel network for self-healing and self-cooling', Int. J. Heat Mass Trans., Vol. 66, No. 1, pp.898-905.

Lee, J., Lorente, S., Bejan, A. and Kim, M. (2009) 'Vascular structures with flow uniformity and small resistance', International Journal of Heat and Mass Transfer, Vol. 52, Nos. 7-8, pp.1761-1768.

Lee, M.W., An, S., Yoon, S.S. and Yarin, A.L. (2018) 'Advances in self-healing materials based on vascular networks with mechanical self-repair characteristics', Adv. Colloid Interface Sci., Vol. 252, pp.21-37.

Losa, G., Merlini, D., Nonnenmacher, T. and Weibel, R. (2002) Fractals in Biology and Medicine, Birkhäuser Press, Basel.

McCulloh, K.A., Sperry, J.S. and Adler, F.R. (2003) 'Water transport in plants obeys Murray's law', Nature, Vol. 421, pp.939-942.

Miguel, A.F. (2015) 'Fluid flow in a porous tree-shaped network: optimal design and extension of Hess-Murray's law', Physica A, Vol. 423, pp.61-71.

Miguel, A.F. (2016a) 'Toward an optimal design principle in symmetric and asymmetric tree flow networks', Journal of Theoretical Biology, Vol. 389, pp.101-109.

Miguel, A.F. (2016b) 'A study of entropy generation in tree-shaped flow structures', Int. J. Heat Mass Trans., Vol. 92, pp.349-359.

Miguel, A.F. (2018) 'Constructal branching design for fluid flow and heat transfer', Int. J. Heat Mass Trans., Vol. 122, pp.204-211.

Miguel, A.F. and Rocha, L.A.O. (2018) Tree-Shaped Fluid Flow and Heat Transfer, Springer, New York

Murray, C.D. (1926) 'The physiological principle of minimum work: I. The vascular system and the cost of blood volume', Proc. Natl. Acad. Sci., USA Vol. 12, pp.207-214.

Pepe, V.R., Rocha, L.A.O. and Miguel, A.F. (2017) 'Optimal branching structure of fluidic networks with permeable walls', BioMed Research International, p.5284816. 
Revellin, R., Rousset, F., Baud, D. and Bonjour, J. (2009) 'Extension of Murray's law using a non-Newtonian model of blood flow', Theoretical Biology and Medical Modelling, Vol. 6, pp.1-9.

Rocha, L.A.O., Lorente, S. and Bejan, A. (2014) 'Vascular design for reducing hot spots and stresses', Journal of Applied Physics, Vol. 115, No. 17, p.174904.

Rodríguez-Iturbe, I. and Rinaldo, A. (1997) Fractal River Basins: Chance and Self-Organization, Cambridge University Press, Cambridge.

Senn, S.M. and Poulikakos, D. (2004) 'Laminar mixing, heat transfer and pressure drop in tree-like microchannel nets and their application for thermal management in polymer electrolyte fuel cells', Journal of Power Sources, Vol. 130, Nos. 1-2, pp.178-191.

Uylings, H.B.M. (1977) 'Optimization of diameters and bifurcation angles in lung and vascular tree structures', Bull. Math. Biol., Vol. 39, No. 5, pp.509-519.

Vargas, J.V.C., Ordonez, J.C. and Bejan, A. (2004) 'Constructal flow structure for a PEM fuel cell', Int. J. Heat Mass Trans., Vol. 47, Nos. 19-20, pp.4177-4193.

Wechsatol, W., Lorente, S. and Bejan, A. (2006) 'Tree-shaped flow structures with local junction losses', Int. J. Heat Mass Trans., Vol. 49, Nos. 17-18, pp.2957-2964.

Ziaei, S., Lorente, S. and Bejan, A. (2015) 'Morphing tree structures for latent thermal energy storage', Journal of Applied Physics, Vol. 117, No. 22, p.224901. 